\title{
A política do esporte e a construção do estádio Mineirão
}

\author{
Sports Policy and Construction of the Mineirão Stadium
}

\author{
Wanessa Pires Lott \\ Universidade Federal do Pará, Belém/PA, Brasil \\ Doutora em História, UFMG
}

\begin{abstract}
RESUMO: O presente trabalho tem o objetivo de apresentar a construção do Estádio Magalhães Pinto, popularmente conhecido como Mineirão, localizado em Belo Horizonte, Minas Gerais, Brasil. Destaca-se neste estudo o contexto da política do esporte nacional como fator relevante no processo de edificação do estádio. Assim, como uma partida de futebol, o artigo será apresentado em dois tempos, além da 'concentração', com intuito de uma breve apresentação sobre o tema e do 'apito final' para as últimas considerações. Primeiramente, será feito um panorama das políticas públicas nacionais de esporte, com destaque para a valorização do futebol no estado de Minas Gerais e em seguida o processo de construção e inauguração do Mineirão. A pesquisa, para além da bibliografia acadêmica pertinente, utilizou jornais e revistas de relevância nacional.
\end{abstract}

Palavras-chave: Futebol; Belo Horizonte; Estádio Mineirão; Políticas Públicas.

ABSTRACT: The present work aims to present the construction of the Magalhães Pinto Stadium, popularly known as Mineirão, located in Belo Horizonte, Minas Gerais, Brazil. In this study, the context of national sports policy stands out as a relevant factor in the process of building the stadium. Thus, like a football match, the article will be presented in two stages, in addition to 'concentration', with the intention of a brief presentation on the topic and 'final whistle' for the last considerations. First, an overview of national public sports policies will be made, with emphasis on the valorization of football in the state of Minas Gerais and then the construction and inauguration process of Mineirão. The research, in addition to the pertinent academic bibliography, used newspapers and magazines of national relevance.

KeYwords: Football; Belo Horizonte; Mineirão Stadium; Public Policies. 


\section{A CONCENTRAÇÃO: UMA BREVE INTRODUÇÃO AO TEMA}

Inserido no Brasil nos primeiros anos da República como um esporte para as elites, o futebol ganhou o status de uma modalidade esportiva capaz de moldar o corpo e promover competições amigáveis - fair play - entre os pares. No entanto, aos poucos foi sendo abraçado pelo povo, tornando-se uma das paixões nacionais. ${ }^{1}$ Até os anos de 1930 e de 1940, o esporte estava em transição do amadorismo para o profissionalismo e a preocupação com as manifestações populares - como as partidas de futebol - era um ponto de atenção do governo. Assim, a organização dos clubes foi um dos caminhos tomados pelo Estado não só para uma efetiva profissionalização como também como uma forma de controle das massas. Neste sentido, o Estado entrou com efetiva legislação para a organização do esporte e, por conseguinte, a cooptação do futebol para os objetivos de governo, dentre os quais estavam a construção da identidade da recente república brasileira.

É relevante destacar que, para a construção de uma identidade nacional em torno do futebol, os suportes de uma memória coletiva não são apenas as gloriosas vitórias. 0 processo de formação de uma identidade abarca as vitórias, as derrotas, os personagens, os monumentos que irão interligar o passado e o presente por meio de elementos afetivos. Não obstante a memória ser um fenômeno constituído coletivamente, o trabalho de 'enquadramento da memória'2 se faz de maneira compulsória, muitas vezes pela mão do Estado. Dentre este conjunto de suportes, destaca neste artigo o monumento, que aqui será também tomado como um 'lugar de memória'. Estes "nascem e vivem do sentimento que não há memória espontânea" e por isso "é preciso criar arquivos, organizar celebrações, manter aniversários, pronunciar elogios fúnebres, notariar atas, porque estas operações não são naturais". Assim, os 'lugares de memória' são construídos. São espaços onde a memória pode ser constantemente relembrada por meio de um dado ritual. Desta maneira, se tomarmos o estádio de futebol como um 'lugar de memória',

\footnotetext{
${ }^{1}$ DA MATTA Antropologia do óbvio - Notas em torno do significado social do futebol brasileiro.

2 O termo 'enquadramento da memória' foi retirado do texto de POLLAK, Memória e Identidade Social. Sobre o tema de memória e identidade ver, não só os estudos deste autor como também de HALBWACHS, A memória coletiva.
} 
percebermos que a memória do futebol é constantemente retomada em cada partida, em cada comemoração no estádio.

Assim sendo, mais uma vez é assertiva a postura dos governantes de construir estádios imponentes para consolidar a memória e a identidade nacional por meio do futebol. $\mathrm{Na}$ esteira deste pensamento e, utilizando como procedimentos metodológicos a pesquisa bibliográfica, a análise da legislação e de periódicos coerente ao tema, o estudo aqui proposto irá apresentar primeiramente um panorama das políticas públicas em torno do esporte, com destaca para o futebol. Em seguida, o estádio do Mineirão será tomado como um exemplo da reafirmação das ações políticas do governo em prol da valorização do futebol bem como da afirmação do governo vigente.

\section{PRIMEIRO TEMPO: A POLÍTICA ESPORTIVA}

Em âmbito nacional, o segundo governo Vargas (1937-1945) retomou as ideias de construção da identidade nacional do primeiro governo e elegeu o esporte, principalmente o futebol, como um ponto de grande relevância para a estruturação da nação. Acreditou-se "no poder mobilizador do futebol e, consequentemente, em sua relevância como elemento na construção de um pensamento nacional que aglutinasse diferentes opiniões e segmentos". ${ }^{3}$ Assim, as políticas públicas em torno da questão do esporte ganharam fôlego com a criação do Conselho Nacional de Desportos (CND) em 14 de abril de 1941 por meio do decreto-lei 3.199. Vinculado ao Ministério de Educação e Saúde Pública, o intuito foi de estabelece as bases de organização dos desportos em todo o país. O CND fazia a filiação, regia as penalidades e intervia na administração interna das entidades esportivas. Além disso, o registro, o contrato de atletas e a autorização para haver competições também ficaram a cargo do conselho, ou seja, o setor esportivo privado foi cooptado pela administração pública. ${ }^{4}$

\footnotetext{
${ }^{3}$ BRINATI; MOSTARO. Maracanã como mídia urbana: as narrativas jornalísticas, apropriações e interações no torcer no "maior do mundo", p. 214.

${ }^{4}$ MANHÃES. Política de Esportes no Brasil.
} 
Art. $3^{\text {o }}$ Compete precipuamente ao Conselho Nacional de Desportos: a) estudar e promover medidas que tenham por objetivo assegurar uma conveniente e constante disciplina à organização e à administração das associações e demais entidades desportivas do país, bem como tornar os desportos, cada vez mais, um eficiente processo de educação física e espiritual da juventude e uma alta expressão da cultura e da energia nacionais (grifo meu). ${ }^{5}$

É importante também destacar a vinculação do esporte com a questão da alta cultura e como fonte de energia para o país. Tais pontos vão ao encontro das políticas desenvolvimentistas cunhadas na época de Vargas, as quais pretendiam inserir o Brasil no grupo dos países 'modernos', 'civilizados' e 'desenvolvidos'. A ideia do 'esporte a serviço da pátria' de Mazzoni, ${ }^{6}$ produziu diversas deliberações no governo Vargas, ${ }^{7}$ bem como conquistas importantes para este esporte, como a realização da Copa do Mundo no Brasil.

No dia "primeiro de julho de 1946, os representantes das nações filiadas à Federação Internacional de Futebol (FIFA) reunidos em Luxemburgo aprovaram por unanimidade a designação do Brasil como anfitrião da IV Copa do Mundo" que foi realizada em $1950 . .^{8}$ Para tal, o antigo sonho de erguer um monumental estádio na capital federal começou a ser concretizado. Assim, aliado à concepção higienista e eugenista de Vargas, a edificação monumento grandioso como um 'lugar de memória’ para o futebol se faz pertinente para o governo. “Defender a construção do Maracanã significava dar à cidade do Rio um reforço simbólico de sua importância como capital, dentro de um projeto de modernização proposto pelo Estado brasileiro".9

\footnotetext{
${ }^{5}$ BRASIL Decreto n. 3.199 de 14 de abril de1941 - Estabelece as bases de organização dos desportos em todo o país.

${ }^{6}$ O termo 'o esporte a serviço da pátria' foi retirado do livro homônimo lançado em 1941 pelo jornalista esportivo Thomaz Mazzoni (1900-1970). Para o autor, o esporte era um dos caminhos para constituir a identidade nacional além de engrandecer o país. Ver MAZZONI, $O$ esporte a serviço da pátria.

7 Sobre as deliberações do CND no governo Vargas ver VERONEZ, Quando o Estado joga a favor do privado: as políticas de esporte após a Constituição de 1988.

8 SARMENTO. A regra do jogo: uma história institucional da CBF p.72. A princípio o campeonato seria realizado em 1949, mas os dirigentes solicitaram o adiamento de um ano. Assim, a Copa do Mundo no Brasil foi realizada em 1950. Ver SARMENTO, A regra do jogo: uma história institucional da CBF.

${ }^{9}$ SANTOS. Maracanã: símbolo das disputas e da complexidade das modernas contradições brasileiras p. 24.
} 
Mesmo com a derrota da Copa de 1950, fato este considerado por Vargas como a 'vergonha nacional', o futebol se manteve como o esporte mais cultuado no país e o grande ápice para nação foi a conquista da Copa do Mundo de 1958. Esta vitória abrilhantou o governo desenvolvimentista do mineiro Juscelino Kubitschek de Oliveira, ${ }^{10}$ que por sua vez deu sequência às polícias públicas em prol do esporte iniciadas no governo varguista sem grandes modificações. JK manteve o CND e aprovou o regimento da Divisão de Educação Física (DEF), este último com o intuito de "difundir e aperfeiçoar a educação física e os desportos, a fim de contribuir para a melhoria das condições de saúde e de educação do povo". Neste sentido, o esporte passou a influenciar significativamente as práticas de Educação Física nas escolas, reforçando as diretrizes da CND ${ }^{11}$. Nos boletins da DEF, os artigos sobre treinamento esportivo eram cada vez mais frequentes e intuito do governo foi ampliar a atuação da divisão nos estados.

O Decreto n. 49.639/1960 ampliava sua estrutura, criando as inspetorias seccionais de educação física (ISEF), objetivando expandir a ação do DEF no nível regional. Inicialmente foram criadas 18 inspetorias, todas em capitais de estados, com as mesmas funções do DEF, ou seja, orientar, fiscalizar e executar mediadas visando ao desenvolvimento da educação física. ${ }^{12}$

Não obstante as alterações da DEF e a vitória do Brasil na Copa de 1958 e de 1962, o governo desejava um maior crescimento do país em competições internacionais. Assim, desenvolveu em 1958 a Campanha Nacional de Educação Física (CNEF) ${ }^{13}$ e Plano Diretor de Educação Física e dos Desportos em 1964, este último sob a regência do governo João Goulart. Com o golpe civil militar de 1964, Goulart é deposto, Ranieri Mazzilli assume o governo por poucos dias e posteriormente passa a faixa presidencial para Castelo Branco. ${ }^{14}$ Este, diferentemente dos seus antecessores, não apresentou forte vinculação com o

10 JK foi eleito governador de Minas Gerais pelo Partido Social Democrático (PSD). Governou entre 31 de janeiro de 1951 a até 31 de março de 1955. Ver CPDOC, Juscelino Kubitschek.

${ }^{11}$ BRASIL Decreto n. 40.296 de 06 de novembro de 1956 - Aprova o Regimento da Divisão de Educação Física, do Ministério da Educação.

12 VERONEZ. Quando o Estado joga a favor do privado: as políticas de esporte após a Constituição de 1988 p. 200.

${ }^{13}$ A CNEF foi instituída pelo Decreto n. 43.177/58. Posteriormente a campanha ganhou maior fôlego como o Decreto n. 53.741/1964. Este reafirmou os deveres do Estado frente ao esporte. ${ }_{14}$ Humberto de Alencar Castelo Branco se manteve no poder entre 15 de abril de 1964 e 15 de março de 1967 CPDOC, Castelo Branco. 
futebol, mesmo sendo um dos "elementos mais expressivos da propaganda populista", o esporte não atraiu significativamente "o interesse do grupo castelista". ${ }^{15}$ No entanto, não se pode afirmar que o governo de Castelo Branco não foi neutro ao tema.

O Jornal dos Sports de 22 de maio de 1964 - portanto, menos de dois meses depois do Golpe - menciona com destaque um convite da CBD ${ }^{16}$ aceito por Castelo Branco para esse assistir à partida entre Brasil e Inglaterra, válido pelo Torneio das Nações, competição comemorativa ao cinquentenário da entidade. Em junho de 1965, Castelo parece ter uma aproximação ainda mais evidente da CBD. Nesse período, o Presidente prometeu verba de Cr\$ 500 milhões à entidade para os compromissos da Copa do Mundo do ano seguinte, ainda que João Havelange, presidente da CBD, tivesse informado tempos antes que a entidade não queria receber nada do governo. ${ }^{17}$

Apesar de uma menor relação do presidente com os assuntos de futebol - se compararmos com os presidentes anteriores -, havia uma grande agitação em torno deste esporte após duas vitórias seguidas nas Copas do Mundo de 1958 e 1962. A vitória em 1966 ocasionaria, segundo as regras da FIFA, a posse definitiva do troféu. "A rara oportunidade, desperdiçada anteriormente pelos italianos, levou a direção da CBD a formular um plano de trabalho que buscava adequar as condições ideais de preparação às dificuldades financeiras então enfrentadas". ${ }^{18}$ Somado à readequação financeira, a comissão técnica permitiu uma maior visibilidade dos jogadores durante os treinos, indo ao encontro dos "interesses políticos que envolviam o grande símbolo da nacionalidade". ${ }^{19}$ Desta forma, inúmeros treinos e amistosos foram realizados em diversas cidades a pedido dos prefeitos que desejavam uma projeção política às custas da seleção brasileira de futebol. Tal prática reforçou as questões já observadas desde o decreto-lei n. 3.199/1941, no qual o Estado aproximou dos clubes e consequentemente os

${ }^{15}$ COUTO. Da ditadura à ditadura: uma história política do futebol brasileiro (1930-1978), p. 134.

${ }^{16}$ A Confederação Brasileira de Desportos (CBD) foi o órgão responsável pela organização do esporte no Brasil. Foi fundada em 20 de agosto de 1914, em 24 de setembro de 1979 passou a ser chamada Confederação Brasileira de Futebol (CBF). Tal mudança estava estritamente relacionada ao decreto da FIFA, no qual as entidades de futebol deveriam ser exclusivas para este esporte. Ver SARMENTO, A regra do jogo: uma história institucional da CBF.

17 LOPES. As interferências e interlocuções de Castelo Branco no futebol e os precedentes para a militarização do futebol brasileiro, p. 29.

18 SARMENTO. A regra do jogo: uma história institucional da CBF, p. 118.

${ }^{19}$ SARMENTO. A regra do jogo, p. 118. 
dirigentes de clubes aproximaram dos palanques políticos. Assim, “a eliminação precoce [que] foi decretada pela equipe de Portugal, mas parecia já se esboçar no confuso processo de preparação para o torneio". ${ }^{20}$

Na esfera do Estado de Minas Gerais, a questão das políticas públicas em torno do esporte estava a cargo da Diretoria de Esportes de Minas Gerais (DEMG), instituição essa que existiu entre os anos de1946 a 1987.21 Alinhada aos preceitos do governo federal, a DEMG seguiu o intuito de promover atividades "para a ocupação do tempo de não trabalho, disciplinando os corpos para as exigências da produtividade; de contribuir para o aprimoramento eugênico do brasileiro" - no que tange principalmente a época do governo Vargas - além de reforçar o "espírito nacionalista, conseguido por meio dos "talentos esportivos e suas conquistas". ${ }^{22}$ Durante a maior parte de sua existência, esta diretoria ficou ligada diretamente ao governador - salvo no interregno de 1963 a 1967 que esteve vinculada à Secretaria de Estado do Trabalho e Cultura Popular - e manteve forte relação com o Minas Tênis Clube da capital. De acordo com o decreto de 1946, “a Diretoria de Esportes de Minas Gerais compor-se-á de três membros, nomeados pelo Chefe do Governo do Estado, e mais o presidente do Minas Tênis Clube, seu membro nato". ${ }^{23}$ Ademais, a DEMG manteve a íntima relação entre o Estado e os dirigentes de clubes, aos moldes do CND, já que a diretoria deveria “opinar, junto ao Governo do Estado, quando solicitada, sobre as pessoas que julgar em condições de serem nomeadas para a presidência dos clubes (...) ou sugerir a sua substituição, quando isto lhe parecer conveniente". 24

Dentre as ações políticas mais significativas, a construção de praças esportivas se destacou, medida esta que foi, mais uma vez, em comunhão com o governo federal. Com intuito de incentivar o esporte nas escolas, as praças deveriam

\footnotetext{
20 SARMENTO. A regra do jogo, p.121.

${ }^{21}$ A DEMG foi criada por meio do Decreto-Lei n. 1.765 de 17 de junho de 1946 durante o curto governo interventor João Tavares Corrêa Beraldo do PSD, que durou do dia 03 de fevereiro de 1946 até 12 de agosto de 1946.

${ }^{22}$ COSTA; RODRIGUES. Diretoria de Esportes de Minas Gerais, p. 48.

${ }^{23}$ MINAS GERAIS, Decreto-Lei n. 1.765 de 17 de junho de 1946 - Muda a denominação da Diretoria Geral das Praças de Esportes de Minas Gerais, altera sua constituição e contém outras disposições, art. $2^{\circ}$.

${ }^{24}$ MINAS GERAIS, Decreto-Lei n. 1.765 de 17 de junho de 1946 - Muda a denominação da Diretoria Geral das Praças de Esportes de Minas Gerais, altera sua constituição e contém outras disposições, art. $4^{\circ}$.
} 
"ser frequentadas por alunos dos grupos escolares, em horário que for combinado, para prática de exercícios físicos". ${ }^{25}$ A organização do espaço era feita pela Polícia Militar de Minas Gerais, que também orientava a prática de educação física.

Essa aproximação da Polícia Militar com a DEMG era uma forma de o governo assegurar que fossem inculcados, nos jovens, valores ligados à ordem, disciplina, obediência e civismo, inerentes à organização social que se pretendia legitimar. Resolveria, também, o problema da carência de pessoal habilitado para a atuação nas praças de esportes, uma vez que não havia em Minas Gerais, naquela época, outros cursos de formação em Educação Física, além do Centro de Educação Física do Departamento de Instrução da Polícia Militar, que foi um núcleo de formação de instrutores e monitores dessa especialidade. ${ }^{26}$

Durante o governo estadual de JK, a DEMG ampliou suas funções e foi responsável pela promoção da cultura e do turismo no estado, além organizar o Conselho Regional de Desportos (CRD), órgão vinculado ao CND. Em 1957, a diretoria passou por mais uma reformulação e destacou como "centro de organização, orientação, difusão e fiscalização de educação física, dos desportos e da recreação" com atuação "nas entidades esportivas, estabelecimentos oficiais e particulares de ensino, núcleos de classes trabalhadoras, órgão de assistência social e estabelecimentos congêneres". Com o intuito de "estimular o desenvolvimento racional da educação física, dos desportos e da recreação" no Estado. ${ }^{27}$

A construção de praças se manteve de forma acelerada e contou com recursos financeiros da Loteria do Estado de Minas Gerais a partir de 1961,28 no governo de Bias Fortes. ${ }^{29}$ Também houve a maior inserção dos profissionais de educação física nos quadros da DEMG, facilitado a real promoção do esporte e da recreação. Seis meses depois foram promulgadas outras diretrizes da diretoria devido à troca de governo. A rivalidade entre o antigo governador, Bias Fortes e o

${ }^{25}$ MINAS GERAIS, Assembleia Legislativa de Decreto-Lei n. 922, de 16 de junho de 1943 Dispõe sobre concessão do uso e gozo das praças de esportes Minas Gerais e sua administração, art. $4 \stackrel{0}{-}$

${ }^{26}$ COSTA; RODRIGUES. Diretoria de Esportes de Minas Gerais, p. 52-3.

${ }^{27}$ MINAS GERAIS, Assembleia Legislativa de Decreto n. 5349, de 05 de novembro de 1957. Contém o regulamento da Diretoria dos Esportes de Minas Gerais, art. 1‥

${ }^{28}$ Esta medida de utilizar os recursos da Loteria para a promoção do esporte, também foi utilizada também como forma de viabilizar a construção do estádio Minas Gerais, conforme será trabalhado no tópico seguinte deste artigo.

${ }^{29}$ Bias Fortes foi eleito governador de Minas Gerais pelo Partido Social Democrático (PSD) com apoio de JK. Governou entre 31 de janeiro de 1956 e 31 de janeiro de 1961. Ver CPDOC, Bias Fortes. 
então eleito, Magalhães Pinto, ${ }^{30}$ fez com que diversos decretos fossem rapidamente promulgados. Na prática, as mudanças giraram em torno do fim das parcerias com as Escolas de Educação Física e um maior esclarecimento entre as relações do Estado, dos municípios e dos clubes esportivos para a construção das praças esportivas. Não obstante a ideia da construção do estádio Minas Gerais advir do antigo governador, Magalhães Pinto abraçou o projeto, vislumbrando estes como um grande alavancar de sua carreira política em Minas Gerais.

\section{INTERVALO EM IMAGENS}

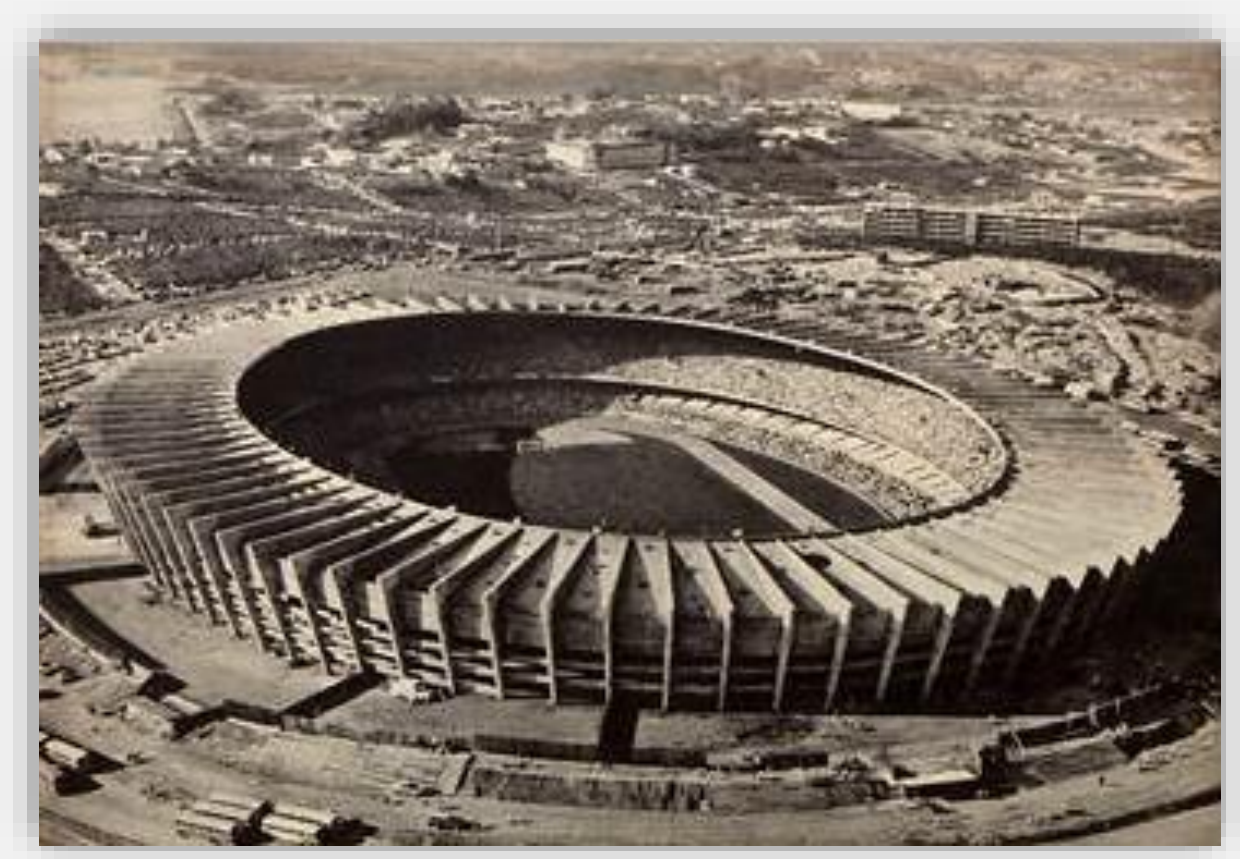

Fig. 1: Vista aérea do estádio Minas Gerais no dia de sua inauguração. Fonte: Manchete.

\footnotetext{
30 Magalhães Pinto foi eleito governador de Minas Gerais por uma coligação liderada pela União Democrática Nacional (UDN). Governou entre 31 de janeiro de 1961 e 31 de janeiro de 1966. Ver CPDOC, Magalhães Pinto.
} 


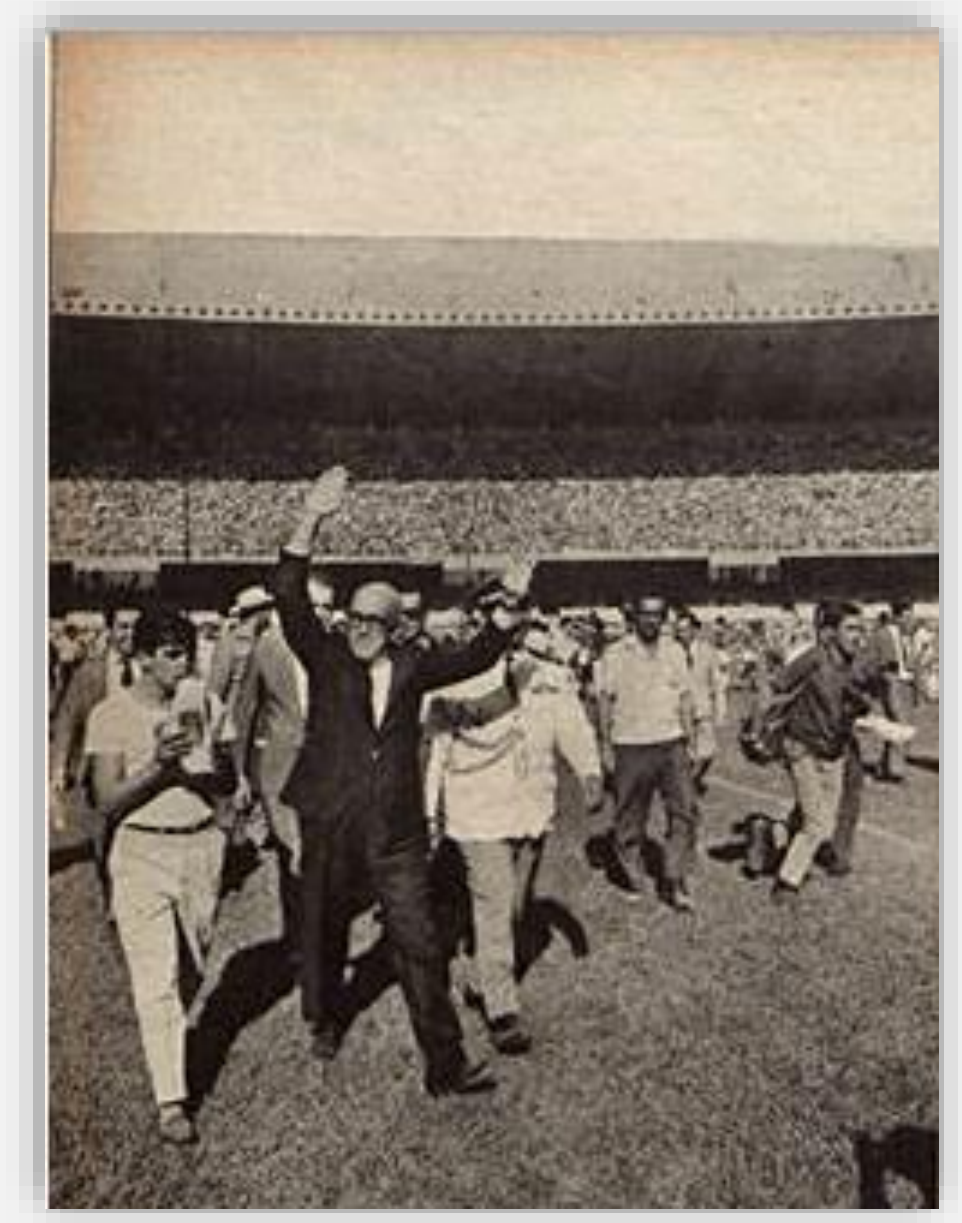

Fig. 2: Magalhães Pinto na inauguração do estádio Minas Gerais. Fonte: Manchete.

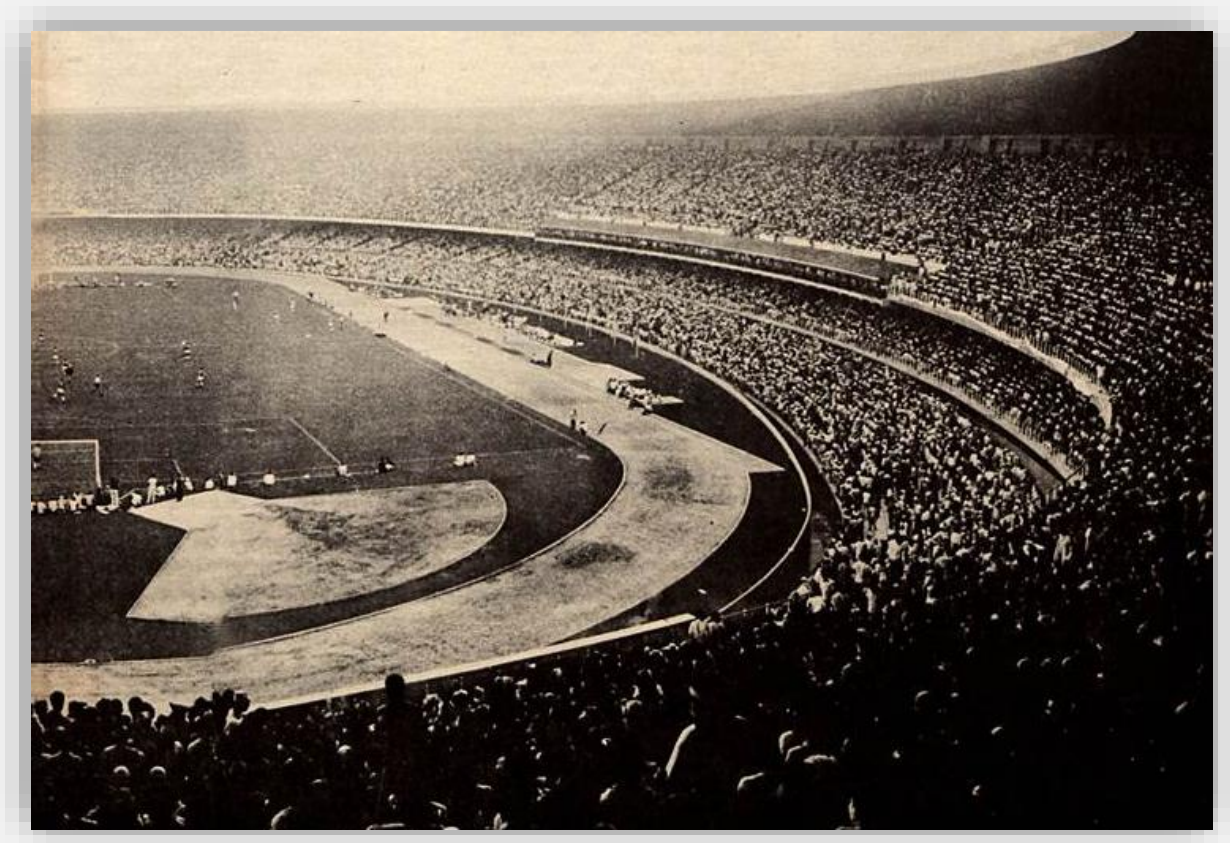

Fig. 3: Inauguração do estádio Minas Gerais. Fonte: Manchete. 


\section{SEgUNDO TEMPO: ERGUE-SE O GigANTE DA PAMPULHA}

Na esteira dos projetos de promoção do futebol pelo governo federal, iniciaram em Minas Gerais os debates a respeito da construção de um novo estádio de futebol em Belo Horizonte. Não obstante a recente inauguração do Estádio do Independência e as reformas significativas nos demais estádios da cidade, os periódicos locais apontavam a necessidade de mais um espaço para o futebol. ${ }^{31}$ As reclamações giravam em torno da estrutura física, pois os estádios belohorizontinos não apresentavam locais reservado para o jornalismo - "locutores e técnicos das rádios ficam dentro do campo" -, e nem entrada e saída independente para os jogadores - "é expressamente impraticável o estádio que não possui túnel para entrada e saída dos litigantes". ${ }^{32}$ Ademais, com o crescente número de torcedores, os estádios locais não comportavam os espectadores sedentos pelo esporte. Não obstante o estádio Independência ter capacidade para 30 mil pessoas e os demais da cidade comportarem 10 mil, a demanda por espaço era crescente.

Diante desde cenário, o então governador do Estado, Juscelino Kubitschek de Oliveira consolidou em 1954 uma comissão responsável para a construção do novo estádio, mas as discussões não prosseguiram. Quatro anos mais tarde, a Federação Mineira de Futebol apresentou à prefeitura um projeto de um estádio a ser construído às margens da BR-3 (atual BR-040), que seria financiado pela venda de cadeiras cativas e mais uma vez o projeto não se concretizou. ${ }^{33}$ Então, no ano de 1959, o deputado estadual Jorge Carone do Partido Republicano (PR) apresentou um projeto para a construção do novo estádio que foi sancionado como lei no dia 13 de maio de 1959 pelo governador José Francisco Bias Fortes.

Art. 1ํ Fica o Poder Executivo autorizado a construir em Belo Horizonte, em terreno de propriedade do Estado, ou que adquirir ou lhe venha a ser doado, um Estádio - que se denominará "Minas Gerais" - para a prática do futebol e atletismo, com capacidade para cem mil espectadores (...). Art. 6ํㅜ A Loteria do Estado de Minas Gerais cobrará de

\footnotetext{
${ }^{31}$ Sobre os estádios de futebol de Belo Horizonte, ver o estudo de SOUZA NETO, Do Prado ao Mineirão: a história dos estádios na capital inventada.

${ }^{32}$ FOLHA DE MINAS, p. 7. "O jornal Folha de Minas foi diário fundado em 14 de outubro de 1934, em Belo Horizonte, pela sociedade anônima Folha de Minas mantenedora do jornal (...). Encerrou suas atividades em novembro de 1964". APM, Folha de Minas.

${ }^{33}$ SANTOS. Estádio Mineirão: orgulho e redenção do futebol mineiro.
} 
seus agentes, sobre o custo real do bilhete de cada extração, uma taxa de dez por cento, que será assim distribuída: (...) IV - quatro por cento para construção do Estádio Minas Gerais. ${ }^{34}$

Como a Federação Mineira de Esporte já havia iniciado um projeto para a construção de um estádio, esta entregou os projetos para a Diretoria de Esportes de Minas que foi responsável pela a obra. ${ }^{35}$

Art. 9o Fica a Diretoria de Esportes de Minas Gerais autorizada a indenizar à Federação Mineira de Futebol a importância de $\operatorname{Cr} \$$ 1.080.000,00 (hum milhão e oitenta mil cruzeiros) correspondente às entradas iniciais, no valor de $\mathrm{Cr} \$ 7.200,00$ (sete mil e duzentos cruzeiros) cada uma, da venda de cento e cinqüenta cadeiras perpétuas do estádio que a federação programava construir. § 1으 Para o recebimento da indenização prevista neste artigo, a Federação Mineira de Futebol se obriga a entregar gratuitamente à Diretoria de Esportes de Minas Gerais os estudos, plantas, projetos e especificações relativos ao estádio que programava construir. $\S 2^{\circ}$ A despesa resultante deste artigo correrá por conta da quota destinada por esta lei ao Estádio Minas Gerais. ${ }^{36}$

Com o financiamento garantido, a escolha do terreno contou com a parceria entre Ministério da Educação e Cultura, o Conselho de Administração do Estádio Minas Gerais, a Diretoria de Esportes do Estado de Minas Gerais e a Universidade

\footnotetext{
${ }^{34}$ MINAS GERAIS. Assembleia Legislativa de Lei n. 1947, de 13 de agosto de 1959. Dispõe sobre a construção de um estádio em Belo Horizonte, para a prática do futebol e atletismo, e contém outras providências.

${ }^{35}$ Art. $2^{\circ}$ A construção do Estádio e, posteriormente, sua administração ficarão a cargo da Diretoria de Esportes de Minas Gerais, que será assistida por um Conselho de Administração composto de dez membros, sem direito a remuneração, os quais serão designados pelo Governador do Estado da seguinte forma: I - um representante do Governo do Estado; II - um representante da Assembleia Legislativa, indicado pela sua Comissão Executiva; III - um representante da Prefeitura Municipal de Belo Horizonte, indicado pelo Prefeito; IV - um representante da Câmara Municipal de Belo Horizonte; V - um representante da Federação Mineira de Futebol; VI - um representante dos clubes profissionais, indicado pelo Conselho Divisional da Federação Mineira de Futebol; VII - um representante da Diretoria de Esportes de Minas Gerais, indicado pela sua Diretoria; VIII - um representante da Associação Mineira de Cronistas Esportivos, indicado pela respectiva Diretoria; IX - um representante da Federação Universitária Mineira de Esportes; X - um representante do Conselho Regional de Desportos. $\S$ 1 O mandato do Conselho será por tempo indeterminado, ficando sua substituição, que dependerá da homologação do Governador do Estado, a critério do órgão que o indicou. § $2^{\circ}$ É permitida a recondução dos membros do Conselho. MINAS GERAIS, Assembleia Legislativa de Lei n. 1947, de 13 de agosto de 1959. Dispõe sobre a construção de um estádio em Belo Horizonte, para a prática do futebol e atletismo, e contém outras providências.

${ }^{36}$ MINAS GERAIS, Assembleia Legislativa de Lei n. 1947, de 13 de agosto de 1959. Dispõe sobre a construção de um estádio em Belo Horizonte, para a prática do futebol e atletismo, e contém outras providências.
} 
de Minas Gerais (UMG), ${ }^{37}$ sendo esta última a doadora do espaço. Em contrapartida, a universidade recebeu o Centro Esportivo Universitário (CEU) para as atividades dos docentes, que foi inaugurado em 08 de março de $1971 .^{38}$

Os estudos para a elaboração do projeto contaram com pesquisas em diversas localidades. Além do Maracanã, os estádios do Japão, Suíça, Inglaterra, França, Portugal, México, Iugoslávia, Canadá e Hungria foram foco de análise. ${ }^{39}$ As obras do estádio, conhecido como Mineirão ou Gigante da Pampulha, iniciaram na gestão do governador Bias Fortes e deram sequência - a princípio a contragosto devido as posturas políticas contrárias - com seu sucessor José Magalhães Pinto. ${ }^{40}$ A construção ganhou mais força à medida que se aproximava a data prevista para a inauguração e a cada mês contratou-se mais operários sob a orientação do engenheiro chefe Gil César Moreira de Abreu. 0 reforço financeiro veio por meio da venda das cadeiras cativas e contou com o Pelé para aquecer a publicidade, como nos relata um dos membros da Diretoria de Esportes de Minas Gerais, Ulysses Panisset. "Trouxemos o Pelé, que tinha acabado de ganhar, mais uma Copa e tal, o Pelé estava igual a um menino; [...] não tinha 18 anos feito, tinha 17 anos e pouco. E o Pelé veio para fazermos a campanha de divulgação das cadeiras cativas. ${ }^{41}$

Com a conclusão das obras, as comparações com os demais estádios brasileiros afloraram: o estádio Minas Gerais com a capacidade para 100 mil torcedores era maior que o Independência e mais moderno que o carioca Maracanã.

Qual a diferença entre o Maracanã e o Minas Gerais? O Maracanã é maior, porém o Minas Gerais é mais moderno. Seu aspecto geral segue a tradicional linha elíptica inglesa, enquanto o Maracanã é circular. Neste, a distância do último degrau da arquibancada ao centro do campo é de 126 metros e, no Minas Gerais, apenas 90 metros. Os mineiros vêem o jogo mais de perto. E também não apanham chuva, pois uma grande marquise, como vão livre de 28 metros, cobre todas as localidades. Além disso, terão mais luz para os jogos noturnos, fornecida por um sistema de 240 refletores - 20 a mais do que o Maracanã - que é a última palavra no assunto. 42

\footnotetext{
37 “Instituição pública de ensino superior gratuito, é a mais antiga universidade do estado de Minas Gerais. Sua fundação ocorreu em 07 de setembro de 1927 com o nome Universidade de Minas Gerais (UMG)". Posteriormente a instituição foi alterada para Universidade Federal de Minas Gerais. UFMG, A universidade.

${ }^{38}$ CEU, Estrutura do Clube.

39 BIANCHI. O gigante de Minas.

${ }^{40}$ COSTA; RODRIGUES. Diretoria de Esportes de Minas Gerais.

41 PANISSET apud COSTA; RODRIGUES. Diretoria de Esportes de Minas Gerais, p. 77.

42 BIANCHI. O gigante de Minas, p. 20.
} 
Os elogios traçados pela revista carioca Manchete ${ }^{43}$ continuam ao afirmar que, não obstante os gramados do Maracanã e do estádio Minas Gerais serem do mesmo tamanho - 110 por 90 metros - a grama, trazida da Índia e da Inglaterra, era "inigualável, de um verde puro, uniforme e viçosa", comparável com o estádio londrino de Wembley e do Vale do Jamor de Lisboa. A drenagem do campo era perfeita e o acesso a este era feito por túneis "que se ligam aos 5 vestiários, aparelhados com banheiras térmicas, gabinetes médicos, oxigenoterapia ${ }^{44}$ e salas de massagem". Ademais, havia "36 bares, 86 sanitários, 24 cabines com arcondicionado para rádio e tevê (...) além de uma área de 100 mil metros quadrados para estacionamento de 5 mil veículos". ${ }^{45}$

Mesmo com a obra inacabada - no entanto mais finalizada ao se comparar com o dia da inauguração do Maracanã - os operários comemoraram a préinauguração com um churrasco no dia 17 de julho. 0 grande festejo ficou para o dia 05 de setembro de 1965 com a presença do então governador Magalhães Pinto (fig. 2) e com a vitória da Seleção Mineira sobre o River Plate da Argentina, por um gol do atleticano Buglê (fig. 3). No dia 07 de setembro as festas de inauguração continuaram com a partida da seleção brasileira - que foi formada pela equipe do Palmeiras - contra a seleção do Uruguai. A vitória foi dos brasileiros por 3 a 0.46 Anos após a inauguração, o estádio ganha o nome de "Estádio Governador Magalhães Pinto", em homenagem ao governador que conduziu a maior parte das obras até sua finalização.

\section{O APITO FINAL: À GUISA DE UMA CONSIDERAÇÃO FINAL}

O futebol "é uma atividade dotada de uma notável multivocalidade - uma vocação complexa que permite entendê-lo e vivê-lo simultaneamente de muitos pontos de

43 "Manchete foi uma revista semanal de grande circulação, lançada no Rio de Janeiro (RJ) em 26 de abril de 1952, tendo circulado regularmente até 29 de julho de 2000. Criada pelo imigrante ucraniano Adolpho Bloch, (...) a publicação se estabeleceu como principal concorrente da então extremamente bem-sucedida revista O Cruzeiro, dos Diários Associados, de Assis Chateaubriand, a qual viria a superar (...). Com seu slogan "Aconteceu, virou Manchete" - atingiu seu ápice, firmando-se como verdadeiro fenômeno editorial: chegou a ter tiragem de milhões de exemplares naquele período. BNDIGITAL, Manchete.

${ }^{44}$ A oxigenoterapia é um tipo de tratamento que pode ajudar atletas a se recuperarem de lesões.

${ }^{45}$ BIANCHI. O gigante de Minas, p. 20.

${ }^{46}$ MINEIRÃO. História. 
vista. Neste estudo, o futebol foi tomado na ótica das políticas públicas bem como na relevância de um grandioso 'lugar de memória' para este esporte". ${ }^{47}$ Percebemos que sta multivocalidade foi tomada pelo Estado como uma forma de constituição da identidade brasileira, por meio do disciplinamento e cooptação do esporte em prol do Estado. Assim, as políticas públicas pautaram no entendimento que o futebol poderia transformar os corpos dos homens para a formação de uma sociedade saudável para o trabalho da pátria. O Estado de Minas Gerais seguiu as diretrizes do governo federal, e as ações políticas foram ao encontro da construção de um monumento para o futebol: o estádio Mineirão. Não obstante as dificuldades iniciais para a consolidação do sonho, o palco do futebol foi inaugurado e ganhou elogios da mídia. Ao ser comparado à grande obra da capital do Brasil, o estádio Maracanã, reforçou-se a identidade não só brasileira, mas principalmente a mineira em torno do futebol.

\section{REFERÊNCIAS}

APM - Arquivo Público Mineiro. Folha de Minas. Disponível em: https://bit.ly/3iaNz2b. Acesso em: 28 abr. 2020.

BIANCHI, Ney. O gigante de Minas. Manchete. Rio de Janeiro, n. 700, p. 18-21, 18 set. 1965. Disponível em: https://bit.ly/38GrvsT. Acesso em: 30 abr. 2020.

BNDIGITAL - Biblioteca Nacional Digital. Manchete. Disponível em: https://bndigital.bn.gov.br/artigos/manchete. Acesso em: 30 abr. 2020.

BRASIL. Decreto n. 3.199 de 14 de abril de1941 - Estabelece as bases de organização dos desportos em todo o país. Disponível em: https://bit.ly/2XEBoB9. Acesso em: 07 maio 2020.

BRASIL. Decreto n. 40.296 de 06 de novembro de 1956 - Aprova o Regimento da Divisão de Educação Física, do Ministério da Educação. Disponível em: https://bit.ly/38NbAtb. Acesso em: 07 maio 2020.

BRASIL. Decreto n. 43.177 de 07 de fevereiro de 1958 - Institui a campanha nacional de educação física. Disponível em: https://bit.ly/3bDlz4J. Acesso em: 07 maio 2020.

47 DA MATTA. Antropologia do óbvio, p. 12. 
BRINATI, Francisco Ângelo; MOSTARO, Filipe. Maracanã como mídia urbana: as narrativas jornalísticas, apropriações e interações no torcer no "maior do mundo". Revista Rua, Campinas/SP, v. 24, n. 1, p. 211-236, jun. 2018.

CPDOC - Centro de Pesquisa e Documentação de História Contemporânea do Brasil. Bias Fortes, 2020c. Disponível em: https://bit.ly/3nJNeEw. Acesso em: 30 abr. 2020.

CPDOC - Centro de Pesquisa e Documentação de História Contemporânea do Brasil. Castelo Branco, 2020b. Disponível em: https://bit.ly/3bEV0gE. Acesso em: 30 abr. 2020.

CPDOC - Centro de Pesquisa e Documentação de História Contemporânea do Brasil. Juscelino Kubitschek, 2020a. Disponível em: https://bit.ly/3oKqjKR. Acesso em: 30 abr. 2020.

CPDOC - Centro de Pesquisa e Documentação de História Contemporânea do Brasil. Magalhães Pinto, 2020d. Disponível em: https://bit.ly/2XDgwdo. Acesso em: 30 abr. 2020.

CEU - Centro Esportivo Universitário. Estrutura do Clube. https://www.ufmg.br/ceu/site/estrutura. Acesso em: 30 abr. 2020.

COSTA, Luciana Cirino Lages Rodrigues; RODRIGUES, Marilita Aparecida Arantes. Diretoria de Esportes de Minas Gerais: suas políticas, sua história (1946-1987). In: ISAYAMA, Hélder Ferreira; RODRIGUES, Marilita Aparecida Arantes. (Orgs.). Um olhar sobre a trajetória das políticas públicas de esporte em Minas Gerais: 1927 a 2006. Belo Horizonte: UFMG, 2013.

COUTO, Euclides de Freitas. Da ditadura à ditadura: uma história política do futebol brasileiro (1930-1978). Niterói: Editora da UFF, 2014.

DA MATTA, Roberto. Antropologia do óbvio - Notas em torno do significado social do futebol brasileiro. Revista USP - Dossiê Futebol, n. 22, p. 10-17, 1994.

FOLHA de Minas. Belo Horizonte, 11 jul. 1958.

HALBWACHS, Maurice. A memória coletiva. São Paulo: Centauro, 2013.

LOPES, Lucas S. As interferências e interlocuções de Castelo Branco no futebol e os precedentes para a militarização do futebol brasileiro. Cantareira, p. 23-33, jul.dez., 2019.

MANHÃES, Eduardo Dias. Política de Esportes no Brasil. Rio de Janeiro: Graal. 1986.

MAZZONI, Thomaz. O esporte a serviço da pátria. São Paulo: Olimpicus, 1941.

MINAS GERAIS, Assembleia Legislativa de. Decreto-Lei n. 922, de 16 de junho de 1943 - Dispõe sobre concessão do uso e gozo das praças de esportes Minas Gerais e sua administração. Disponível em: https://bit.ly/3nDA8J6. Acesso em: 29 abr. 2020.

MINAS GERAIS, Assembleia Legislativa de. Decreto-Lei n. 1.765 de 17 de junho de 1946 - Muda a denominação da Diretoria Geral das Praças de Esportes de Minas Gerais, altera sua constituição e contém outras disposições. Disponível em: https://bit.ly/3sp3YVc. Acesso em: 30 abr. 2020. 
MINAS GERAIS, Assembleia Legislativa de. Decreto n. 5349, de 05 de novembro de 1957. Contém o regulamento da Diretoria dos Esportes de Minas Gerais. Disponível em: https://bit.ly/2Kckdnk. Acesso em: 29 abr. 2020.

MINAS GERAIS, Assembleia Legislativa de. Lei n. 1947, de 13 de agosto de 1959. Dispõe sobre a construção de um estádio em Belo Horizonte, para a prática do futebol e atletismo, e contém outras providências. Disponível em: https://bit.ly/39Bhehb. Acesso em: 29 abr. 2020.

MINAS GERAIS, Assembleia Legislativa de. Decreto n. 6107, de 09 de janeiro de 1961. Contém o regulamento da Diretoria dos Esportes de Minas Gerais Disponível em: https://bit.ly/38GNZdm. Acesso em: 29 abr. 2020.

MINEIRÃO, Estádio. História. Disponível em: http://estadiomineirao.com.br/omineirao/historia/. Acesso em: 01 maio 2020.

NEVES, Jader; CAVALCANTI, Domingos; ALMEIDA, Gaspar de. O gigante de Minas. Manchete. Rio de Janeiro, n. 700, p. 18-21, 18 set. 1965. Disponível em: https://bit.ly/2LN8sEo. Acesso em: 30 abr. 2020.

POLLAK, Michael. Memória e Identidade Social. Estudos Históricos, Rio de Janeiro, v. 5, n. 10, p. 200-212, 1992.

SANTOS, André Carazza dos. Estádio Mineirão: orgulho e redenção do futebol mineiro. Efdeportes Revista Digital, Buenos Aires, año 10, n. 87, 2005.

SANTOS, Felipe Oliveira. Maracanã: símbolo das disputas e da complexidade das modernas contradições brasileiras. Entropia, Rio de Janeiro, v. 3, n. 6, p. 22-52, jul.-dez., 2019.

SARMENTO, Carlos Eduardo. A regra do jogo: uma história institucional da CBF. Rio de Janeiro: CPDOC, 2006.

SOUZA NETO, Georgino Jorge de. Do Prado ao Mineirão: a história dos estádios na capital inventada. Tese (Doutorado em Estudos do Lazer). Escola de Educação Física, Fisioterapia e Terapia Ocupacional da UFMG, Belo Horizonte, 2017.

UFMG - Universidade Federal de Minas Gerais. A universidade. Disponível em: https://ufmg.br/a-universidade. Acesso em: 30 abr. 2020.

VERONEZ, Luiz Fernando Camargo. Quando o Estado joga a favor do privado: as políticas de esporte após a Constituição de 1988. Campinas: UNICAMP - Faculdade de Educação Física, 2005. 